\title{
Isolation of Bacteriophage from Eggs and Use of Excreta as Biocontrol Agent in Controlling Eggs Related Salmonellosis
}

\author{
Md. Abu Sayem Khan ${ }^{1}$,Md. Muktadir Rahman Ashik² and Sabita Rezwana Rahman ${ }^{1 *}$ \\ ${ }^{1}$ Department of Microbiology, University of Dhaka,Dhaka-1000, Bangladesh, ${ }^{2}$ Incepta Vaccine Ltd, Savar, Dhaka, Bangladesh.
}

\begin{abstract}
Poultry and poultry products are the leading causes of foodborne salmonellosis worldwide. Antibiotics are used to control Salmonella spp. in poultry but its uncontrolled use results in the emergence of resistant pathogens. The use of bacteriophages as antimicrobial agents to control antibiotic resistant pathogenic bacteria could be a possible alternative. The aimof this study was to isolate,characterize and evaluate the effectiveness of bacteriophages for reducingload of Salmonella spp. on eggshells. One bacteriophage named as Sal-PE, specific to Salmonella enteritidiswas isolated from poultry excreta. For isolation, samples were subject to an enrichment protocol and then double agar layer method was performed to detect plaque. It had the capability to survive in wide range of $\mathrm{pH}$ between 4 to 10 and found to be resistant at $60^{\circ} \mathrm{C}$ for 1 hour. Sal" PE showed its lytic effect on 13 of the $15(87 \%)$ isolates including Salmonella enteritidis and Salmonella typhimurium which were recovered from 50 poultry excreta samples. After enrichment and growth on selective media, isolates were identified based on cultural characteristics, microscopic observation and biochemical tests. Amplification of three different genes (invA, sdfI, fliC) were carried out tocharacterize those isolates in molecular level. All isolates were found to be resistant to penicillin $\mathrm{G}$, ampicillin, oxacillin and clindamycin but sensitive to ciprofloxacin, streptomycin, cefixime and chloramphenicol. Lytic efficiency of Sal-PE was determined by observing the reduction in optical density due to destruction of pathogens. Though more studies are needed in order to evaluate phage effectiveness, our findingsare expected to help us in initiating the development of a better preventive approach to control the occurrence of Salmonella spp. on eggshells.
\end{abstract}

Keywords: Poultry, Salmonellosis, Antibiotic resistance, Bacteriophage, Biocontrol.

\section{Introduction}

Salmonella is a Gram-negative bacterium and is one of the main causes of foodborne illness throughout the world. Poultry and poultry products are known to contain Salmonella spp., and consumption of these contaminated foods may cause foodborne diseases. Eggs and egg products are recognized as most frequent carrier of Salmonella spp. during salmonellosis outbreaks in humans, representing $43.7 \%$ of cases ${ }^{1}$. Salmonellosis is one of the major infections that not only affects commercial poultry but also threatens public health ${ }^{2}$. Eggs can be contaminated with bacterial pathogens by following both horizontal (eggshell penetration, environmental contamination) and vertical (transovarian) route of transmission ${ }^{3}$.

Many strategies have been followed to control Salmonella spp. in poultry and poultry products. Washing with water, irradiation, chemicals are used to reduce the number of Salmonella spp.on eggshell but they cause problems like increasing chance of cross contamination, deterioration of egg quality etc. Antibiotics are frequently used as feed additives to prevent bacterial diseases but continuous evolution of antibiotic resistance is a global concern due to its improper use. So, Scientists are now focusing on bacteriophages for pathogen control in poultry.
Bacteriophages, the bacteria predating viruses, are ubiquitous in nature ${ }^{4}$. There are two different types of bacteriophages. Lytic phages replicate inside host after infection and lyse host at the end of replication whereas lysogenic phages integrate their DNA in their host and transfer it to another host. Because of enormous bactericidal capability, application of lytic bacteriophages is counted as an emerging treatment for combating bacterial infections.

Poultry production is a promising and fast growing industry in Bangladesh economy. It can be a potential tool for poverty reduction and economic development. But contamination by Salmonella spp. creates problems that adversely affects poultry sector. Besides, Salmonella spp. infection is identified as a prime constraint that impedes the development of poultry industry ${ }^{5}$. As antibiotic resistance is common in Bangladesh, it is obvious to put emphasis on developing a cost effective new strategy for controlling the occurrence of Salmonella spp.on eggshells. Occurrence of Salmonella spp. could be reduced by using host-specific bacteriophages ${ }^{6}$. So, host specific bacteriophage isolation, propagation and large scale implementation will provide a safer, more effective, cheaper and environment friendly strategy to eliminate bacterial infections. The aim and objectives of our present

*Corresponding author:

Dr. Sabita Rezwana Rahman, Professor, Department of Microbiology,_University of Dhaka,Dhaka-1000, Bangladesh.Email: sabita_rahman@hotmail.com 
studies are (1) to isolate and characterize Salmonella spp. and Salmonellaenteritidis specific bacteriophage from poultry excreta, (2) to test the antibacterial activity of isolated phage.

\section{Materials and methods}

\section{Sample collection and processing}

A total of 50 poultry excreta samples were collected from two different poultry farms and one local market near Dhaka city. The cotton swab was inoculated into buffered peptone water and brought to the laboratory for further analysis. $1 \mathrm{~mL}$ of BPW was transferred to selenite cysteine broth and incubated overnight for selective enrichment.

\section{Isolation and of Identification of Salmonella spp.}

One loopful of selenite cysteine broth was streaked onto a xylose lysine deoxycholate (XLD) agar plate and incubated at $37^{\circ} \mathrm{C}$ for $24 \mathrm{hrs}$. Then, the plates were examined for the appearance of Salmonella spp. like red colonies with black centres.

Gram staining was performed for morphological characterization. Then the isolates were subject to several biochemical tests such as catalase test, oxidase test, urease test, kligglers iron agar test, citrate utilization, indole test.

\section{Molecular identification of Salmonella spp.}

Chromosomal DNA was extracted by following boiling DNA method. PCR using several primersfor bacterial chromosomal gene was done for molecular characterization of Salmonellaspp (Table 1).
The PCR reaction was carried out in a thermal cycler (Master Cycler Gradient Thermal Cycler, Eppendorf, Germany). Then amplified PCR products were loaded on a $1.5 \%$ agarose gel stained with ethidium bromide and electrophoresed in $1 \mathrm{X}$ tris borate EDTA buffer. The gel was viewed using Alpha Imager HP Gel documentation system (Cell Bioscience, USA). A 100 bp ladder (Promega, USA) was used a as a marker for PCR products.

\section{Antibiogram of the Salmonella spp. isolates}

Kirby Bauer method was followed for antibiotic susceptibility test of the presumptively selected isolates ${ }^{7}$. A freshly grown isolated colony were transferred into Mueller Hinton broth to obtain young culture. The turbidity of bacterial cultures was then adjusted to a MacFarland 0.5 standard. A sterile cotton swab with adjusted microbial suspension streaked evenly over the entire surface of the Mueller Hinton Agar surface to prepare uniform lawn of bacterial culture. Commercially available antibiotic discs were then placedonto the inoculated plates with sterile forceps and plates were incubated at $37^{\circ} \mathrm{C}$ for $24 \mathrm{hrs}$. Diameters of zones of complete inhibition were measured. The antibiotic discs used were ampicillin,clindamycin, ciprofloxacin, penicillin, chloramphenicol, nalidixic acid, oxacillin, tetracycline and cefixime.

Sample collection and processing for Phage isolation

Another 53 samples were collected from 3 different poultry farm including fresh poultry excreta, dry poultry excreta, poultry sewage, pond water and eggs (Table 2). After collection of sample,

Table 1. Sequences of primer used to characterize isolates

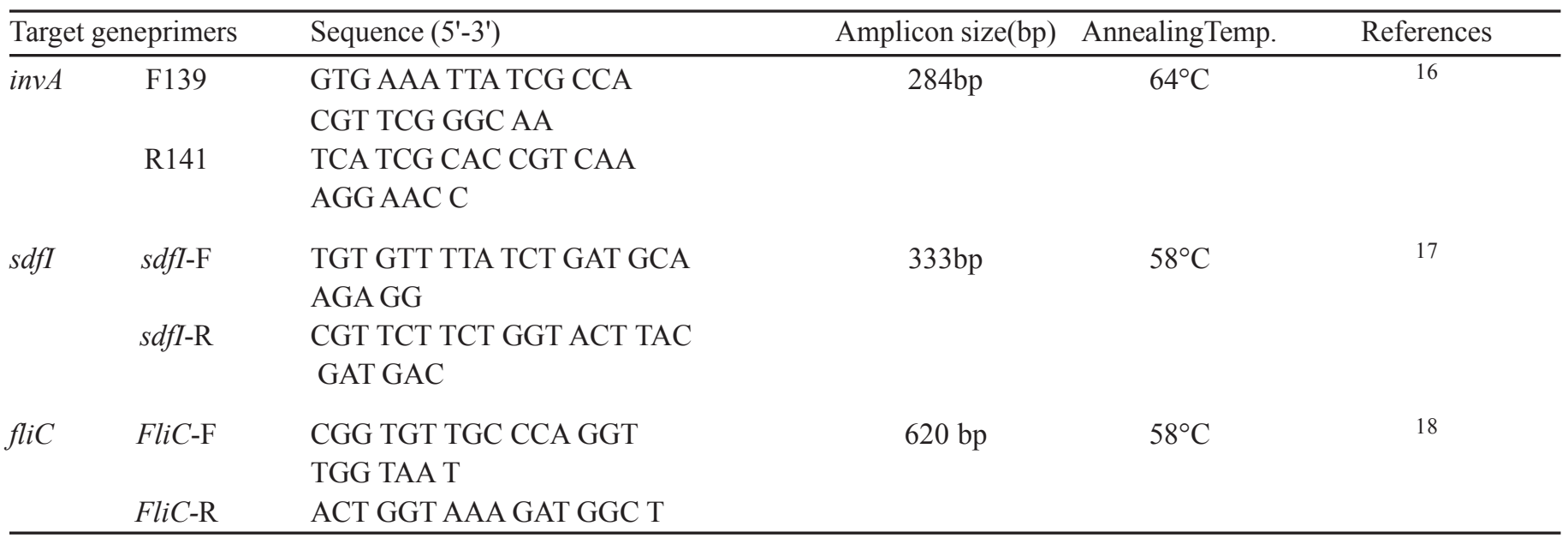

Table 2. Location, type and number of sample collected for phage isolation

\begin{tabular}{llcc}
\hline Sampling location & Sample type & No. of sample & Total no. of samples \\
\hline Kalam poultry farm & Poultry excreta & 12 & 17 \\
& Pond water & 3 & 2 \\
Janata poultry farm & Poultry sewage & 16 & 31 \\
& Poultry excreta & 10 & 5 \\
Finix poultry farm & Eggs & 5 & 05 \\
\hline
\end{tabular}


all samples were held at lowtemperature environment, returned to the laboratory for processing within afew hours of collection.

Solid excreta was mixed with normal saline and vortexed vigorously for detaching phage from solid particles. Eggs were dipped in normal saline, kept for $30 \mathrm{~min}$ and picked up. The tube containing liquid mixture was centrifuged at 10000rpm for 10 $\min$ at $4^{\circ} \mathrm{C}$. After collection of supernatant, the remaining pellet was discarded.

\section{Enrichment of phage sample and phage isolation}

Phage enrichment and isolation was done following methods described by Rahaman et al. ${ }^{8}$ Phage samples were enriched by adding $4.5 \mathrm{ml}$ of samples with $0.5 \mathrm{ml}$ of $10 \mathrm{X}$ nutrient broth and $0.5 \mathrm{ml}$ of log phase reference bacteria followed by overnight incubation. The reference culture KF188421(Salmonella enteritidis) was collected from General Microbiology Laboratory, Department of Microbiology, University of Dhaka.The enriched samples were then centrifuged at $10,000 \mathrm{rpm}$ for $10 \mathrm{~min}$ at $4^{\circ} \mathrm{C}$. Supernatants were taken,passed through $0.45 \mu \mathrm{M}$ syringe filter,collected in sterile glass vial and further used for phage isolation. To perform spot test, bacterial lawn was prepared by spreading $1 \mathrm{ml}$ of freshly grown bacteria on nutrient agar plate. The plates were allowed to dry after removing excess fluid. Then a drop of $15 \mu \mathrm{l}$ of filtrated supernatant was placed on the agar surface forcefully and incubated at $37^{\circ} \mathrm{C}$ for overnight for lytic spot detection.

Plaque assay was done toisolate the bacteriophage freshSalmonella host reference culture. $100 \mu \mathrm{l}$ of hostbacteria and $100 \mu \mathrm{l}$ of filtrated supernatant were mixed with $3.5 \mathrm{ml}$ of soft agar ( $0.7 \%$ nutrient agar). After gentle mixing, the suspension was then poured onto a previously prepared nutrient agar (1.5\%) plate,spreadeduniformly, allowed for $10 \mathrm{~min}$ to solidify. Then the plates incubated overnight at $37^{\circ} \mathrm{C}$. Plaques were observed and counted the next day.

\section{Phage expansion and purification}

Individual plaques were picked up using an inoculating loop. The loop was touched on the center of the plaques and swirled to obtain a single plaque. The plaque was then suspended in distilled water, and an over- lay method was used to obtain purified plaques.

A plate with confluent lysis was selected for phage purification and $10 \mathrm{ml} \mathrm{SM}$ buffer supplemented with gelatin was poured on the plate. The plate was incubated at $4^{\circ} \mathrm{C}$ overnight. Few drops of $\mathrm{CHCl}_{3}$ was added in collected supernatants and mixed gently. Then it was centrifuged at $5000 \mathrm{rpm}$ for $15 \mathrm{~min}$. Then supernatant was collected using a syringe and filtered by $0.45 \mu \mathrm{M}$ syringe filter. The filtrate was preserved in a sterile tube for further use.

\section{Host range determination}

All the previously isolatedSalmonella spp. were usedto determine thehost range of Sal-PE. Fresh culture of bacteria was prepared by inoculating a single colony in nutrient broth and placed it in a shaker. $100 \mu \mathrm{L}$ of sub-culture was inoculated into $3.5 \mathrm{~mL}$ of molten nutrient agar, poured onto nutrient agar plates, allowed to solidify. $15 \mu \mathrm{l}$ of bacteriophage preparation was dropped on cultures of bacterial isolates and incubated overnight.The plates were observed for the appearance of lytic clear zones.

Study of the effect of temperature and $p H$ on the stability of phage For observing the effect of different temperatures on phage stability, tubes with phages were kept in a water bath ranging from $30^{\circ} \mathrm{C}$ to $90^{\circ} \mathrm{C}$ for $60 \mathrm{~min}$.

Sample of bacteriophage were subject to different $\mathrm{pH}$ ranging from 4 to 10 . The $\mathrm{pH}$ of the nutrient broth was adjusted using $\mathrm{NaOH}$ or $\mathrm{HCl}$ and incubated at $37^{\circ} \mathrm{C}$ for 30 min followed by plaque assay.

\section{Antibacterial activity of phage}

The phage treated test tubes contained $4.5 \mathrm{ml}$ nutrient broth, $0.5 \mathrm{ml}$ fresh culture of bacteria and $100 \mu \mathrm{l}$ of bacteriophage. On the other hand, In phage free control set, $100 \mu \mathrm{L}$ of sterile normal saline was added instead of bacteriophage. Both tubes were then incubated at $37^{\circ} \mathrm{C}$ overnight. Optical density of both phage treated and untreated samples was taken at $600 \mathrm{~nm}$ to measure phage mediated killing.

\section{Results}

\section{Isolation and Identification of Salmonella spp.}

15 isolates were presumptively identified as Salmonella spp. on the basis of microscopic examination and biochemical tests. All the isolates produced black centred colonies on XLD agar and found to be Gram negative. All of them showed red slant and black butt in KIA, did not hydrolyze urea, did not produce indole and were catalase positive, oxidase negative, MR positive and VP negative which are special biochemical characteristics for Salmonella spp.

\section{Molecular detection of Salmonella spp.}

Salmonella spp. was further confirmed by detection of Salmonella specific gene invA. Primer set used to amplify the invA gene was $\mathrm{S} 139$ and S141. The amplified product (284 bp) was seen in $1.5 \%$ agarose gel (Figure 1 ).

To detect serotype Salmonella typhimuriumfrom isolates, amplification of $f l i C$ was carried out. Distinct band of $620 \mathrm{bp}$ was found in 4 of the 15 isolates.

After amplification of sdfI gene, 4 isolates showed positive band at $333 \mathrm{bp}$. So, among 15 isolates, 4 were found to be Salmonella enteritidis. 


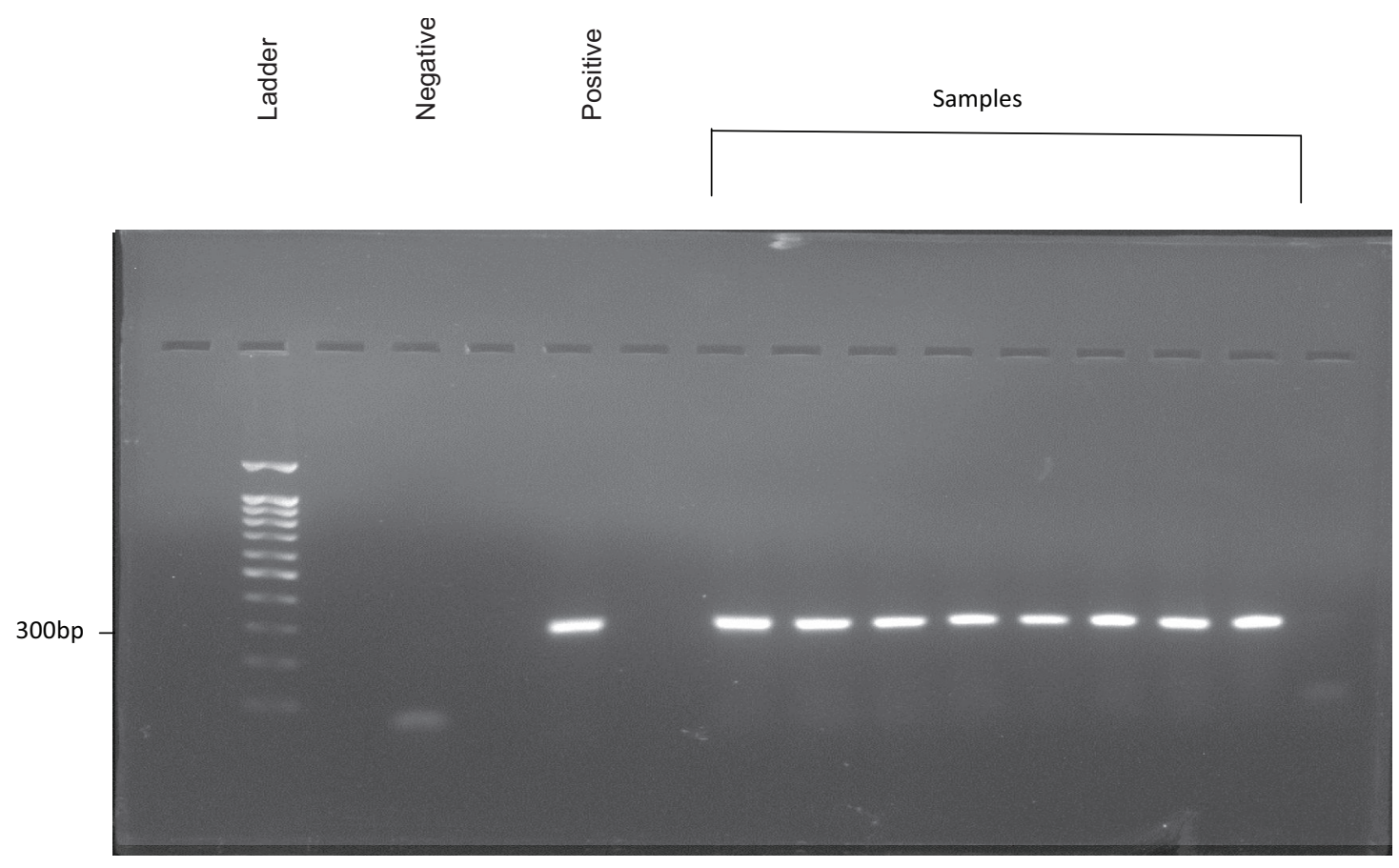

Figure 1. Identification of Salmonella spp. by amplification of invA gene.

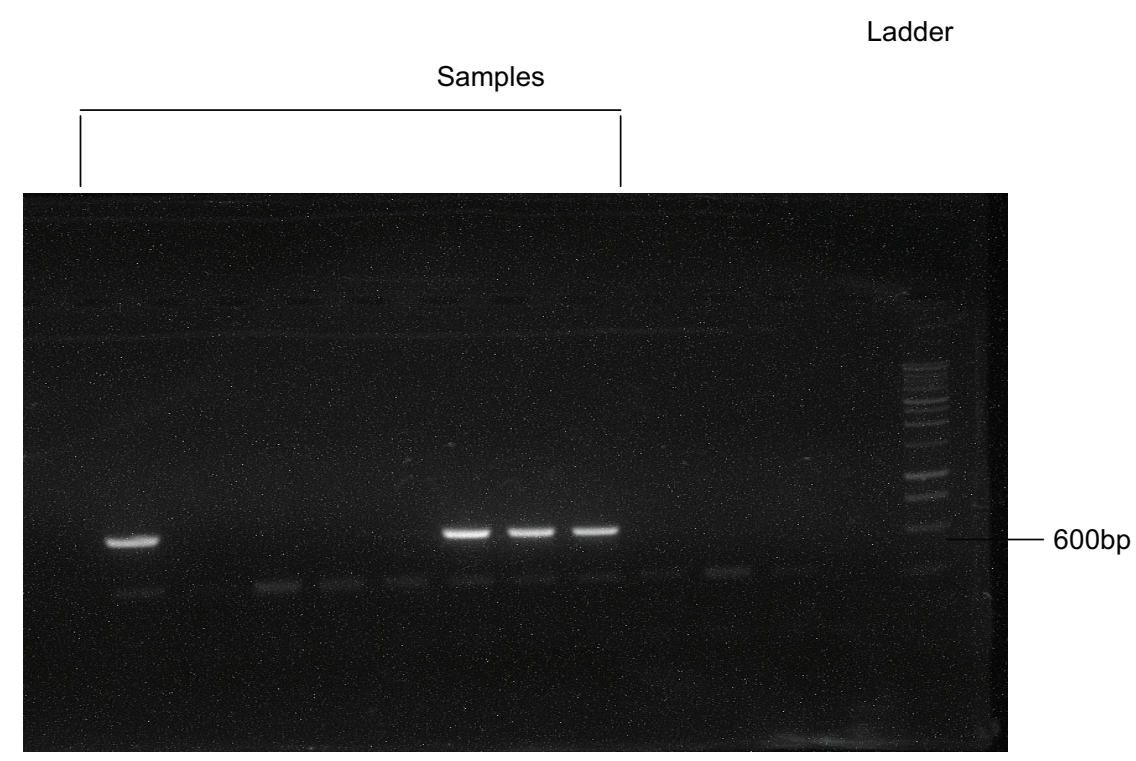

Figure 2. Detection of Salmonella typhimurium

\section{Determination of antibiotic susceptibility of Salmonella spp.}

All the tested isolates were completely resistant to Penicillin G, Ampicillin, Oxacillin (Beta-lactams) and Clindamycin (Lincosamides) and slight variation in drug resistance pattern was found in case of Nalidixic acid (60\%) and Chloramphenicol $(86 \%)$. Organisms showed their sensitivity towards Ciprofloxacin, Cefixime (Cephalosporins) and Streptomycin (Aminoglycoside).

\section{Isolation and purification of bacteriophage}

Initially two Salmonellaenteritidisbacteriophages were isolated by enrichment method. Among them, Sal-PE produced small, lytic clear zone in plaque assay and shown to have broader host range than the other one. For purification of phage, confluent lysis was necessary. Phages were retrieved from confluent lysis and the spot assay was again performed for result validity.This time the plaque was more transparent. Finally the stock titer was determined and it was $2 \times 10^{8} \mathrm{pfu} / \mathrm{mL}$. This stock was diluted to adjust phage and host ratio for physicochemical characterization, determination of host range and antibacterial activity.

\section{Determination of host range}

Sal"PE showed wide host range. The result indicated that Sal"PE had alytic effect on 13 of the 15 isolates (87\%) (Table 3). Itshost range includes Salmonella typhimurium and Salmonella 
Table 3. Host range of bacteriophage Sal-PE

\begin{tabular}{ll}
\hline Isolate & Sal-PE \\
\hline Salmonella spp. & + \\
Salmonella spp. & + \\
Salmonella enteritidis & + \\
Salmonella typhimurium & + \\
Salmonella spp. & + \\
Salmonella enteritidis & \pm \\
Salmonella enteritidis & + \\
Salmonella spp. & + \\
Salmonella typhimurium & + \\
Salmonella typhimurium & " \\
Salmonella typhimurium & \pm \\
Salmonella spp. & + \\
Salmonella spp. & " \\
Salmonella spp. & + \\
Salmonella enteritidis & $\pm=$ faint spot within the inoculated area \\
\hline$+=$ clear spot within the inoculated area formation
\end{tabular}

enteritidis. This test was done in triplicate for the confirmation of results.

\section{Study of physicochemical factors on phage stability}

The results indicated that $\mathrm{Sal}$ "PE was stable between in the range of $30^{\circ} \mathrm{C}$ to $60^{\circ} \mathrm{C}$ for $60 \mathrm{~min}$. No phage was detected at $70^{\circ} \mathrm{C}$, $80^{\circ} \mathrm{C}$ and $90^{\circ} \mathrm{C}$ (Figure 6). So, it can be concluded that the phage was unstable above $60^{\circ} \mathrm{C}$.

Phage was stable from $\mathrm{pH} 4$ to 10 . At the $\mathrm{pH}$ range 6-9, the phage titers were found very close. Phage activity decreased gradually below or above this $\mathrm{pH}$ range (Figure 7). Sal"PE had the capability to survive under wide range of $\mathrm{pH}$.

Bacteriophage mediated killing of host

The optical density was reduced in phage treated bacterial reference culture $(\mathrm{OD}=0.308)$ compared to phage untreated culture $(\mathrm{OD}=0.824)$. Almost $50 \%$ reduction was occurred when culture of Salmonella typhimurium and Salmonella enteritidis was used. The phage untreated test tube (control) appeared to be more cloudy than treated one. As there was no phage in the control, the untreated culture followed normal growth characteristics.

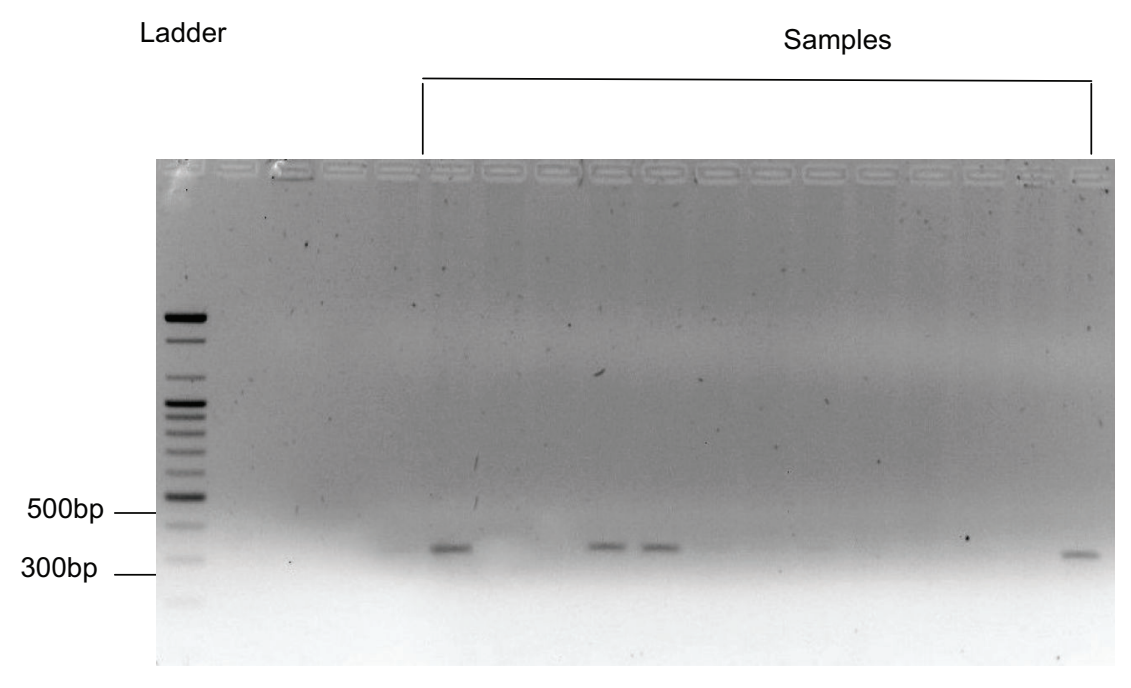

Figure 3. Identification of Salmonella enteritidis 


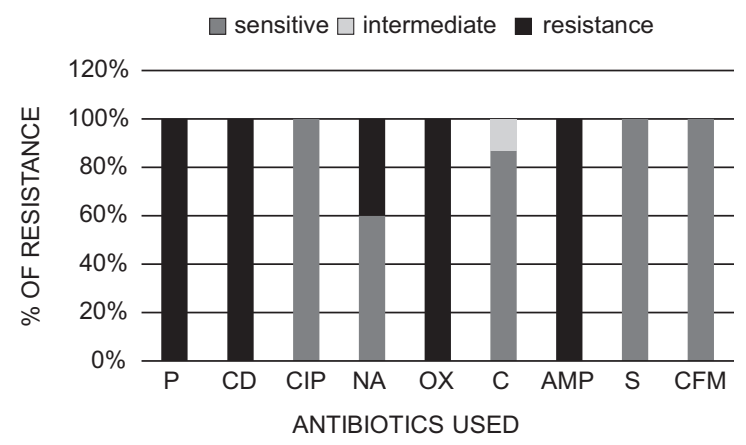

Figure 4. Antibiotic resistance pattern of theisolates $(P=$ Penicillin; $C D=$ Clindamycin; $C I P=$ Ciprofloxacin; $N A=$ Nalidixic Acid; OX=Oxacillin; $C=$ Chloramphenicol; $A M P=$ Ampicillin; $S=$ Streptomycin; $C F M=$ Cefixime )
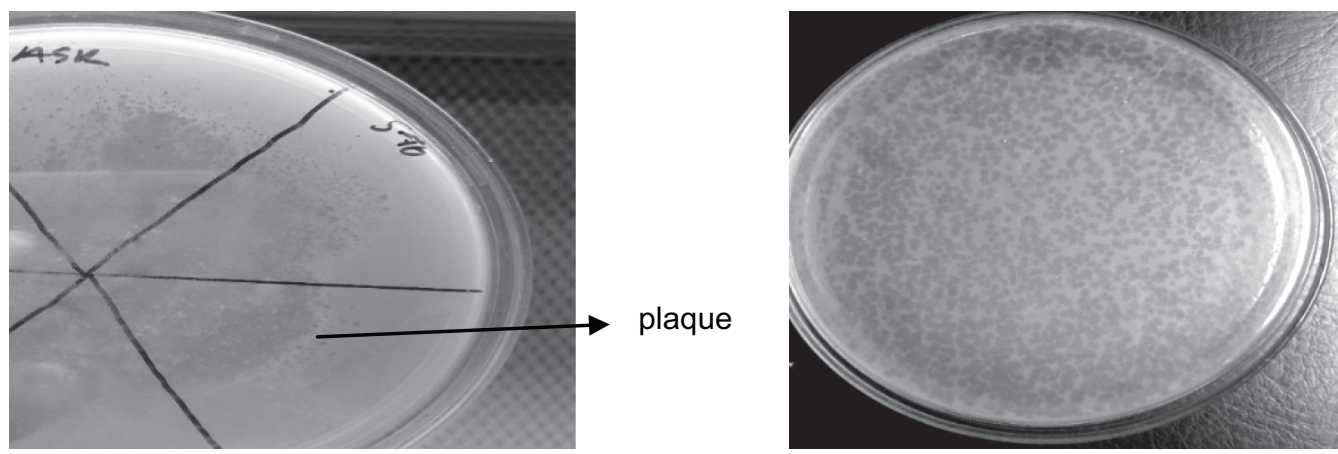

Figure 5. Plaque assay (A) and Confluent lysis of host (B).

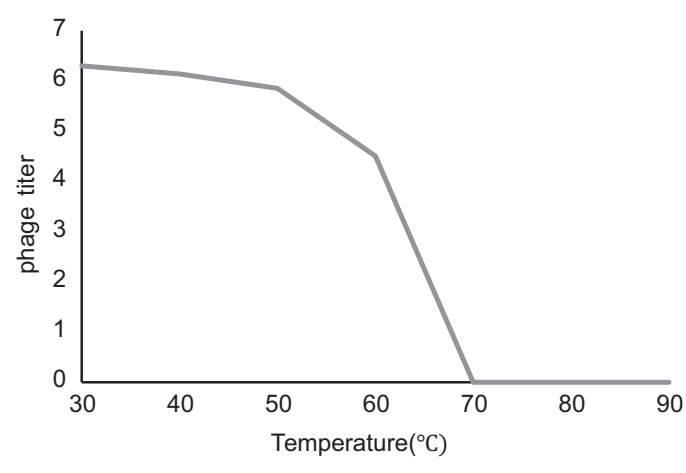

Figure 6. Effect of temperature on the stability of Sal-PE

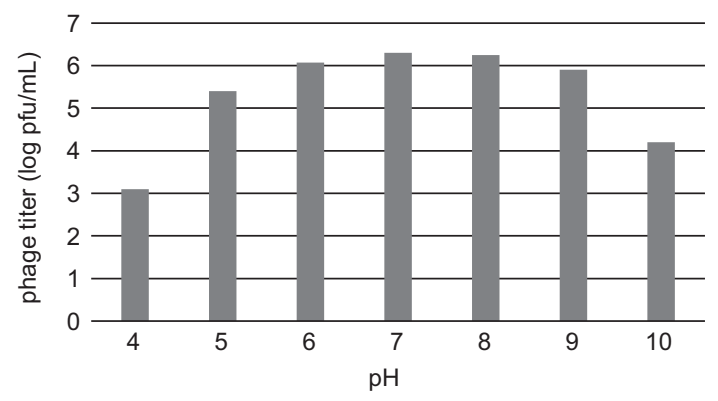

Figure 7. Effect of $p H$ on the stability of Sal-PE

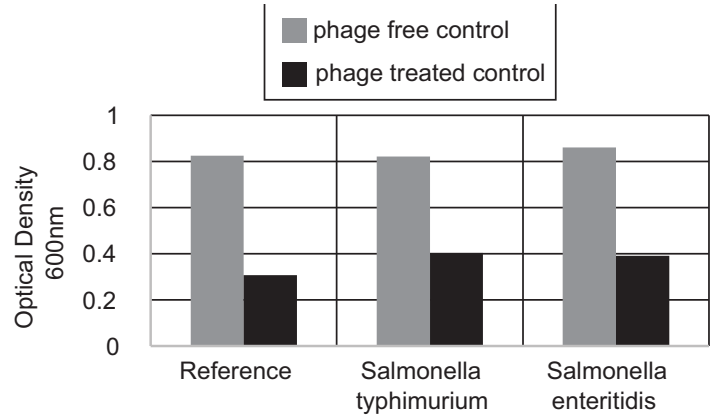

Figure 8. Killing of bacteria by phage in test tubes.

\section{Discussion}

Egg related Salmonellosis is a serious public health issue. Treatment with existing antibiotics appeared to be challenging because of the increased resistance of Salmonella spp. The bacteriophages could provide a natural, safe, cost effective way which can be used asboth therapeutic and prophylacticagents to control Salmonella in poultry ${ }^{6}$. The effectiveness of bacteriophages in reducing viable bacterial counts on raw and processed meats, dairy products, and fresh vegetables have already been reported ${ }^{9}$. In the present study, we isolated Salmonella spp. from different poultry farms, identified and characterized subsequently. Then, the isolation and characterization of specific bacteriophages were done to initiate the development of a biocontrol method. 
In this study, poultry excreta were used for the isolation of Salmonella spp. Food borne pathogens associated with outbreaks are frequently found in excreta. As microbial diversity is high in excreta, selective enrichment for Salmonella was carried out. Observation of the biochemical test patterns was the primary phase of identification. Almost all isolates showed same biochemical pattern except motility. At the end of cultural and biochemical tests, 15 positive Salmonella spp. were isolated which represents $30 \%$ of the collected samples. Amplification of invA gene are now recognised as international standard for rapid and reliable detection of Salmonella spp. ${ }^{10}$. It encodes a virulent inner membrane protein that helps bacteria to invade host epithelial cells ${ }^{11}$. As invA is a virulent gene and all isolates were showed distinct band at 284 bp position, it can be deduced that all the isolates are pathogenic and capable of causing infections upon getting into human body (Figure 1). Amplification of $s d f I$ gene confirmed that 4 of the 15 (27\%) isolates were Salmonella enteritidis (Figure 3) where as 4 out of the $15(27 \%)$ isolates were found positive for $f l i C$ gene which indicated the presence of Salmonella typhimurium (Figure 2). InvA is specific for genus where as $s d f I$ and $f l i C$ are serotype specific.

Isolates were then analysed for antibiogramfollowing the KirbyBauer disk diffusion technique to determine antibiotic susceptibility pattern against 9 antibiotics. The result showed that all isolates were completely resistant to beta lactams (penicillin $\mathrm{G}$, ampicillin and oxacillin) and licosamide (clindamycin). The rate of sensitivity of the isolates to ciprofloxacin, streptomycin, cefixime was $100 \%$ followed by chloramphenicol $(86 \%)$ and nalidixic acid $(60 \%)$ (Figure 4). The reason of antibiotic resistance can be attributed to abuse of antibiotics. Higher occurrence of drug resistant pathogen indicates the poor hygienic condition of poultry farm that is not enough to control Salmonella spp. infection.

It is likely that phage is abundant where there is presence of its host as host is obligately required for phage multiplication ${ }^{12}$. In our study, the samples were from poultry origin like excreta, poultry discharge, pond water and eggs and isolation of phage from these sources indicated that their natural occurrence in the environment. Enrichment was done to increase the number of specific phage. Bacteriophage plaque assay or soft agar overlay assay is a widely used method for phage isolation. Two Salmonella phages were isolated that produced plaques in soft agar. But after host range study, only one phage with wider host range was selected for further study. Bacteriophage Sal-PE formed round, clear, lytic plaques on Salmonella enteritidis lawn. Lytic phages are efficient candidate for phage therapy due to its quick reproduction and lytic capability ${ }^{13}$.

Determination of the host range of the phage is an important step to use phage candidates for serving a specific purpose. Bacteriophage Sal-PE lysed 13 of the 15 (87\%) Salmonella isolates indicating wide host ranges. Almost similar result had been reported by Rahaman et al. ${ }^{8}$ in which the phage lyse $77.77 \%$
Salmonella isolates. Moreover, Bacteriophages SSP5 and SSP6 lysed $65 \%$ of the 41 Salmonella strains indicating its broader host range ${ }^{14}$. Resistance to wide temperature, $\mathrm{pH}$ range is obvious for an efficient biocontrol agent. Sal-PE was relatively stable at $\mathrm{pH} 4$ to 10 . Phage activity was declined at both high and low $\mathrm{pH}$. It also showed that phage Sal-PE lost stability if temperature was above $60^{\circ} \mathrm{C}$. Salmonella enteritidis and Salmonella typhimurium are more commonly associated with poultry and poutry products than other serotypes of Salmonella (Salmonella gallinarum, Salmonella pullorum). Lytic activity against both serotypes and stability at adverse physicochemical parameters will make phage Sal-PE an effective biocontrol agent.

Cocultivation of host bacteria with lytic phages reduces the optical density of bacterial culture is the evident of phage lytic activity ${ }^{15}$. After treatment of reference culture with phage, more than 50\% reduction in optical density in phage treated culturewas achieved compared to phage untreated culture (Figure 8). Same result was also obtained when Salmonella enteritidis and Salmonella typhimurium were employed in studying the effects of phage on host. Killing of host by phage decreased the turbidity in phage treated culture. Reduction in optical density indicated the reduction in the number of bacterial cells due to antibacterial activity of phage.

\section{Conclusion}

Conventional methods for controlling Salmonella cause various problems that cannot ensure food safety. Bacteriophages have emerged as a novel tool for the biocontrol of bacterial contamination in foods. Here we took an approach of phage mediated Salmonella spp. control on eggshell. To sum up, ourisolated phage Sal-PE is a wide host range phage lytic to antibiotic resistant pathogens. Growth at wide range of $\mathrm{pH}$ and temperature makes it efficient in biocontrol applications. Reduction in optical density demonstrates the effectiveness of phage in killing host invitro. Amplification of invA can be a reliable strategy for rapid detection of Salmonella spp.

\section{Reference}

1. EFSA.2012. The European Union summary report on trends and sources of zoonoses, zoonotic agents and food-borne outbreaks in 2010. Euro surveillance: bulletin Europeen sur les maladies transmissibles $=$ European communicable disease bulletin. 17(10).

2. Berchieri Jr A, Murphy C, Marston K and Barrow P.2001. Observations on the persistence and vertical transmission of Salmonella enterica serovars Pullorum and Gallinarum in chickens: effect of bacterial and host genetic background. Avian Pathol. 30(3): 221-231.

3. Chousalkar K, Roberts J, Sexton M, May, D and Kiermeier A.2013. Effects of egg shell quality and washing on Salmonella Infantis penetration.Int $\mathrm{J}$ Food Microbiol. 165(2): 77-83.

4. Sulakvelidze A, Alavidze Z and Morris JG.2001. Bacteriophage therapy. Antimicrob Agents Chemother. 45(3), 649-659.

5. Kamaruddin K and Giasuddin M. 2003. In Poultry disease and its diagnostic facilities. Growth of poultry industry in Bangladesh with poverty alleviation and employment opportunity pp 141-148. Proceedings of 3rd International poultry show and seminar, from February.

6. Atterbury R, Van Bergen M, Ortiz F, Lovell M, Harris J, De Boer A, 
Wagenaar J, Allen V and Barrow P. 2007. Bacteriophage therapy to reduce Salmonella colonization of broiler chickens. Appl Environ Microbiol. 73 (14): 4543-4549.

7. Bauer A, Kirby W, Sherris J C and Turck M.1996. Antibiotic susceptibility testing by a standardized single disk method. Am J Clin Pathol. 45(4): 493.

8. Rahn K, De Grandis S, Clarke R, McEwen S, Galan J, Ginocchio C, Curtiss R and Gyles C.1992. Amplification of an invA gene sequence of Salmonella typhimurium by polymerase chain reaction as a specific method of detection of Salmonella. Mol Cell Probes. 6(4): 271-279.

9. Agron PG, Walker RL, Kinde H, Sawyer SJ, Hayes DC, Wollard J and Andersen GL.2001. Identification by subtractive hybridization of sequences specific for Salmonella enterica serovar Enteritidis. Appl Environ Microbiol. 67(11): 4984-4991.

10. Oliveira S, Santos L, Schuch D, Silva A, Salle C and Canal C.2002. Detection and identification of salmonellas from poultry-related samples by PCR. Vet Microbiol. 87(1): 25-35.

11. Rahaman M, Rahman M, Rahman M, Khan M, Hossen M, Parvej M and Ahmed S.2014. Poultry Salmonella specific bacteriophage isolation and characterization. BangladeshJ. Vet. Med. 12(2): 107-114.
12. Kazi M and Annapure US.2016. Bacteriophage biocontrol of foodborne pathogens. J. Food Sci. Technol. 53(3): 1355-1362.

13. Malorny B, Hoorfar J, Bunge C and Helmuth R.2003. Multicenter validation of the analytical accuracy of Salmonella PCR: towards an international standard. Appl Environ Microbiol. 69(1): 290-296.

14. Darwin KH and Miller VL. 1999. Molecular Basis of the Interaction ofSalmonella with the Intestinal Mucosa. Clin. Microbiol. Rev. 12(3): 405-428.

15. Clokie, MRJ, Millard AD, Letarov AV and Heaphy S.2011.Phages in nature. Bacteriophage. 1(1): 31-45.

16. Abedon ST, Herschler TD, Stopar D.2001. Bacteriophage latent-period evolution as a response to resource availability. Appl Environ Microbiol. 67(9): 4233-4241.

17. Kocharunchitt C, Ross T, McNeil D. 2009. Use of bacteriophages as biocontrol agents to control Salmonella associated with seed sprouts.Int $J$ Food Microbiol. 128(3): 453-459.

18. Quiroz E, Recalde J, Arias MT, Seqqat R, Vinueza C and Ayala L.2016. Isolation of Lytic Bacteriophages for Nanobiocontrol of Pathogenic and Antibiotic Resistant Salmonella Present in Poultry in Ecuador. Biol. Med. 8(3): 1 . 